\title{
Pyp1 and Pyp2 PTPases dephosphorylate an osmosensing MAP kinase controlling cell size at division in fission yeast
}

\author{
Jonathan B.A. Millar, ${ }^{1,2}$ Vicky Buck, ${ }^{1}$ and Marc G. Wilkinson ${ }^{1}$ \\ ${ }^{1}$ Division of Yeast Genetics, National Institute for Medical Research, The Ridgeway, London NW7 1AA, UK
}

\begin{abstract}
Simultaneous inactivation of pyp1 and pyp2 PTPases in fission yeast leads to aberrant cell morphology and growth arrest. Spontaneous recessive mutations that bypass the requirement for pyp 1 and pyp 2 and reside in two complementation groups were isolated, sty 1 and sty2. sty $1^{-}$and sty $2^{-}$mutant cells are substantially delayed in the timing of mitotic initiation. We have isolated the sty 1 gene, which encodes a MAP kinase that is closely related to a subfamily of MAP kinases regulated by osmotic stress including Saccharomyces cerevisiae HOG1 and human CSBP1. We find that sty2 is allelic to the wis1 MAP kinase kinase and that $\Delta$ sty1 and $\Delta$ wis1 cells are unable to grow in high osmolarity medium. Osmotic stress induces both tyrosine phosphorylation of Sty1 and a reduction in cell size at division. Pyp2 associates with and tyrosine dephosphorylates Sty1 in vitro. We find that wis1-dependent induction of pyp 2 mRNA is responsible for tyrosine dephosphorylation of Sty1 in vivo on prolonged exposure to osmotic stress. We conclude that Pyp1 and Pyp2 are tyrosine-specific MAP kinase phosphatases that inactivate an osmoregulated MAP kinase, Sty1, which acts downstream of the Wis1 MAP kinase kinase to control cell size at division in fission yeast.
\end{abstract}

[Key Words: Cell cycle; mitosis; MAP kinase; PTPase; Schizosaccharomyces pombe]

Received May 19, 1995; revised version accepted July 21, 1995.

Growing fission yeast cells tend to divide at a constant size at division. The fission yeast cell cycle is controlled at two major points, in $\mathrm{G}_{1}$ at entry into $\mathrm{S}$ phase (DNA replication) and at the initiation of mitosis. Genetic and physiological studies have revealed that the timing of both transitions requires attainment of a critical cell size and has lead to the proposal that mass sensors govern these cell cycle transitions (Nurse 1975; Fantes and Nurse 1977). Under conditions of normal growth the mass sensor governing the initiation of DNA synthesis is cryptic, such that cell size at division is rate-limiting for cell cycle progression (Fantes and Nurse 1977). Because Schizosaccharomyces pombe cells grow by length extension, this is expressed as the attainment of a critical cell length. Cell size at division can be influenced either by the genotype of the cell or by the prevailing nutritional conditions. The molecular nature of the mass sensors governing these transitions is not known.

A considerable advance in our understanding of the molecular basis of mitotic initiation, nevertheless, has come from the analysis of mutants in fission yeast that uncouple size control from cell cycle progression. In particular the cell division cycle $(c d c)$ mutants have been particularly valuable in identifying the central components of this control (Nurse et al. 1976; Thuriaux et al. 1978; Nasmyth and Nurse 1981). It is now recognized

${ }^{2}$ Corresponding author. that the timing of mitotic initiation is controlled by rapid tyrosine dephosphorylation and activation of the catalytic kinase subunit of the $\mathrm{Cdc} 13$ (cyclin B)/Cdc2 kinase complex by the Cdc25 phosphatase (for review, see Millar and Russell 1992). This complex is maintained in an inactivate state during interphase by the action of the wee1 and mik1 tyrosine kinases (Russell and Nurse 1987a; Lundgren et al. 1991). Structural and functional homologs of the $c d c 2, c d c 13, c d c 25$, and wee1 genes have been shown to exist in metazoa supporting the view that entry into mitosis is controlled by a universally conserved mechanism (Nurse 1990).

Extensive genetic analysis in $S$. pombe has revealed several other sets of genes that show genetic interaction with the core elements described above and, by inference, also encode gene products that control the timing of mitosis. These include win1 and five multicopy suppressors of win1, wis1-wis5 (Ogden and Fantes 1986; Warbrick and Fantes 1991, 1992), the nim1/cdr1 and cdr2 genes (Russell and Nurse 1987b; Young and Fantes 1987), and six mitotic catastrophe suppressors mcs1mcs6 (Molz et al. 1989). The Niml kinase acts to inhibit the Weel tyrosine kinase by direct phosphorylation (Coleman et al. 1993; Parker et al. 1993; Wu and Russell 1993). The wis1 gene, which acts as a dose-dependent initiator of mitosis, encodes a protein that is homologous to a family of MAP kinase kinases (Ogden and Fantes 1986; Warbrick and Fantes 1991). 
This latter observation is particularly intriguing because MAP kinase cascades exist in all eucaryotic cells and have been implicated in a wide range of cellular processes including mitogenic signal transduction, cellular differentiation, and response to environmental stress /for review, see Ammerer 1994; Davis 1994; Marshall 1994; Herskowitz 1995). At least four distinct MAP kinase pathways have been identified in the unicellular budding yeast Saccharomyces cervisiae, which are required for mating, sporulation, control of cell polarity, and the cellular response to osmotic stress. Signal tranduction through MAP kinase cascades involves sequential phosphorylation and activation of three distinct kinases: the MAP kinase kinase kinase (or MEKK), the MAP kinase kinase (or MEK), and the MAP kinase itself. Although there appear to be multiple mechanisms by which plasma membrane-associated receptors can induce activation of MEKK, it has now been demonstrated clearly that MEKK activation leads to MAP kinase kinase activation by direct phosphorylation. The MAP kinase kinase in turn activates the MAP kinase by dual phosphorylation on two closely spaced residues, a threonine and a tyrosine. Less is understood of the mechanisms that terminate signal transduction through MAP kinase cascades, although inactivation of MAP kinases has been ascribed to the action of dual specificity phosphatases that remove both of the phosphates from these residues (Alessi et al. 1993; Sun et al. 1993; Doi et al. 1994; Ward et al. 1994).

We and others recently have identified two additional components of fission yeast mitotic control, pyp1 and pyp2, which encode tyrosine-specific phosphatases. Overexpression of either pyp1 or pyp 2 causes a delay in mitotic initiation. Conversely, disruption of $p y p 1$ and, to a lesser extent, $p y p 2$ causes cells to divide at a reduced cell size. Simultaneous disruption of these genes is lethal, demonstrating that pyp1 and pyp2 share an essential overlapping function (Millar et al. 1992b; Ottilie et al. 1991, 1992). We have constructed a conditional double mutant and undertaken a suppression analysis to investigate the role of $p y p 1$ and pyp 2 in the fission yeast cell cycle. We demonstrate that the pyp1 and pyp2 PTPases regulate a MAP kinase cascade that controls the timing of mitotic initiation in fission yeast. We have identified the central components of this pathway as the the wis1 MAP kinase kinase and a novel MAP kinase, encoded by the sty 1 gene. We show that the sty 1 MAP kinase pathway is regulated by changes in external osmolarity. These studies provide an important link between the cellular response to environmental stress and control of the cell cycle.

\section{Results}

Inactivation of Pyp 1 and Pyp2 causes aberrant cell morphology and growth arrest

Inactivation of either the pyp1 or $p y p 2$ tyrosine-specific phosphatases leads to a reduction in cell size at division in fission yeast. Simultaneous disruption of pyp1 and pyp2 gives rise to inviable spores that do not germinate (Millar et al. 1992b). To examine the role of pyp1 and pyp 2 in the mitotic cell cycle in fission yeast, a conditional allele of pyp 1 under the control of the thiaminerepressible $n m t 1$ promoter was constructed (see Materials and methods). In the absence of thiamine NMT-pyp1 cells divided at $14.3 \pm 0.4 \mu \mathrm{m}$, a size similar to wild-type cells, whereas in the presence of thiamine, cells divided at $11.1 \pm 0.3 \mu \mathrm{m}$, similar to $\Delta p y p 1$ cells (Millar et al. 1992b|. To examine the effects of a loss of pyp1 expression in a $\Delta p y p 2$ strain, NMT-pyp1 $\Delta p y p 2$ cells were grown in the absence of thiamine and then streaked onto minimal medium in the presence of $10 \mu \mathrm{M}$ thiamine. In contrast to wild-type, $N M T-p y p 1$ or $\Delta p y p 2$ cells, NMTpyp1 $\Delta$ pyp2 cells were greatly retarded for growth on medium containing thiamine (Fig. 1A). Microscopic ex-

A
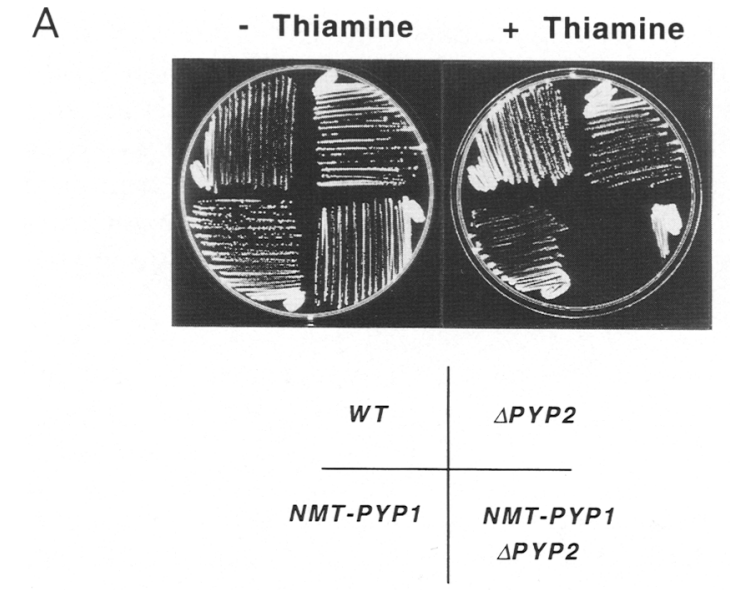

B - Thiamine + Thiamine

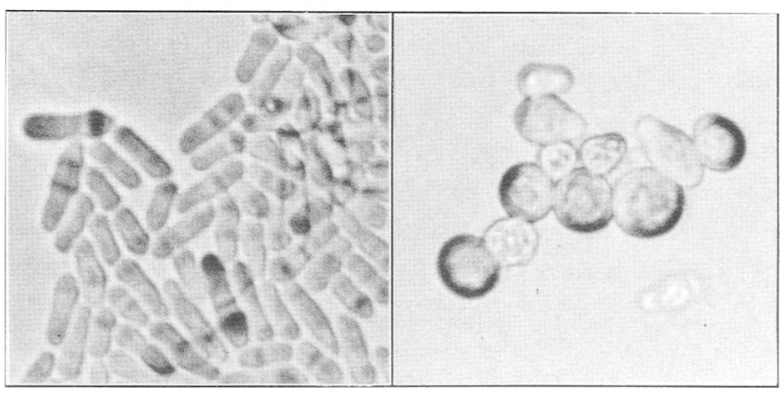

Figure 1. Suppression of pyp1 and pyp2 expression leads to abnormal cell morphology. $(A)$ Cells were grown on minimal medium lacking thiamine and then streaked onto the same medium in the absence (left plate) or presence of $10 \mu \mathrm{m}$ of thiamine (right plate) and allowed to grow for 3 days at $25^{\circ} \mathrm{C}$. The genotypes of the cells were wild-type strain 972 (top left-hand segment), pyp2::LEU2 (top right-hand segment), NMT-pyp1(ura4) (bottom left-hand segment), and NMT-pyp1(ura4) pyp2::LEU2 (bottom right-hand segment). On prolonged incubation NMTpyp1 1 pyp2 cells eventually recovered, presumably because of metabolic depletion of thiamine in the medium. $(B)$ The phenotype of NMT-pyp1(ura4) pyp2::LEU2 cells was examined by phase-contrast microscopy after 3 days growth on minimal medium either in the absence (left) or presence of $10 \mu \mathrm{m}$ of thiamine (right). 
amination revealed that these cells arrested after three or four divisions as large, spherical, swollen cells, a proportion of which lysed (Fig. 1B). In the absence of thiamine, cells were indistinguishable from wild type (Fig. 1B). Growth arrest in the presence of thiamine was not suppressed by the presence of $1 \mathrm{M}$ sorbitol, an osmotic stabilizing agent (data not shown). We conclude that the pyp 1 and pyp 2 genes, in addition to control of mitotic initiation, are required for cell shape control in fission yeast.

\section{styl and sty2 mutants suppress $a \mathrm{pypl}^{-}$pyp2- growth defect}

We utilized the conditional arrest of NMT-pyp1 $\Delta p y p 2$ cells to isolate mutations that bypass the requirement for the pyp 1 and pyp2 PTPases by pseudoreversion analysis. From a total of $10^{7}$ cells plated, 56 fast-growing colonies were identified, of which 17 grew in the absence of thiamine. Cells from all 17 mutant strains were highly elongated relative to wild-type (see below). When outcrossed to a wild type strain the elongated phenotype was found to be unlinked to either the NMT-pyp1 or $\Delta p y p 2$ alleles. Additionally, cross-mating of these strains revealed that these 17 mutants fell into two complementation groups, sty1 (11 alleles) and sty2 (6 alleles) (for suppressor of tyrosine phosphatase). Because all mutants within each complementation group appeared to be elongated to the same extent, a single mutant from each complementation group, sty1-1 and sty2-1, was chosen for further study. Further crosses revealed that both the sty1-1 and sty2-1 mutations segregated 2:2 with respect to the elongated phenotype, indicating that both were the consequence of a single nuclear lesion. To determine whether the sty1-1 and sty2-1 mutations could completely bypass the requirement for pyp1 and pyp2, sty1-1 pyp2::LEU2 or sty2-1 pyp2::LEU2 cells were crossed to pyp $1:$ :ura 4 cells. Spores from both crosses gave rise to colonies of elongated cells that were able to grow in the absence of both uracil and leucine indicating that they had inherited both $\Delta p y p 1$ and $\Delta p y p 2$ alleles. Southern blot analysis was used to confirm the genotypes of the sty1-1 $\Delta$ pyp1 $\Delta p y p 2$ and sty2-1 $\Delta p y p 1 \Delta p y p 2$ triple mutants (data not shown). In a control cross, pyp2::LEU2 was mated to pyp $1::$ ura 4 . From $>3000$ spores analyzed, no colonies grew in the absence of both uracil and leucine, confirming previous observations that simultaneous loss of pyp1 and pyp2 function is lethal (Millar et al. 1992b; Ottilie et al. 1992). These results suggest that both the sty1-1 and sty2-1 mutations were able to bypass the synthetic lethal combination of a $\Delta p y p 1 \Delta p y p 2$ double mutant.

\section{styl and sty 2 mutants are delayed in mitotic initiation}

The role of sty1 and sty2 in the mitotic cell cycle was examined. Growth rates of sty1-1 or sty2-1 cells were found to be identical to wild type with a doubling time of $2.5 \mathrm{hr}$ in rich medium, or $3.5 \mathrm{hr}$ in synthetic minimal medium at $30^{\circ} \mathrm{C}$, indicating that neither mutant was de- fective in cellular growth rate or division. However, when grown to mid-log phase, sty1-1 and sty2-1 mutant cells were found to be substantially longer at division than the wild-type control (Table 1), suggesting that they are delayed in the timing of mitotic initiation. These cells initiate mitosis at a size similar to $c d c 25-22$ cells, which express a partially defective $c d c 25$ phosphatase (Table 1). To investigate further the role of sty1 and sty2 in mitotic control, sty1-1 cells were crossed to $c d c 25-22$ cells and random spore analysis performed. Approximately $25 \%$ of the spores from this cross germinated on YEPD plates at $26^{\circ} \mathrm{C}$ but arrested after one or two divisions as highly elongated cells, suggesting that the sty1-1 cdc25-22 double mutants are synthetically lethal. To confirm this, asci from the same cross were subjected to tetrad dissection. The expected number of PD, TT, and NPD were observed, indicating that $c d c 25$ and sty1 are unlinked genes. At least five NPD tetrads from the same cross had two spores that gave rise to wild-type colonies and two that underwent cell cycle arrest at $26^{\circ} \mathrm{C}$ (Table 1). The inviable cells from these NPDs were classified with the genotype sty1-1 cdc25-22. Identical results were found when crossing sty2-1 to $c d c 25-22$ (Table 1). These data indicate that the products of the sty 1 and sty2 genes are required for the control of cell size at division in fission yeast.

styl and sty 2 mediate mitotic control by the pyp1 and pyp2 PTPases

We have shown previously that overexpression of pyp 1 or pyp2 causes a delay in the timing of mitosis, whereas disruption of either gene has the opposite effect (Ottilie et al. 1991, 1992; Millar et al. 1992b). Two lines of evidence suggest that sty1 and sty2 mediate control of cell size at division by the pyp1 and pyp2 PTPases. First, sty1-1 $\Delta$ pyp1 $\Delta$ pyp2 and sty2-1 $\Delta p y p 1 \Delta p y p 2$ cells initiate cell division at the same size as sty1-1 and sty2-1 single mutants alone (Table 1). Second, no additional delay in mitotic intiation was observed when sty1-1 and

Table 1. Loss of sty1 delays the timing of mitosis

\begin{tabular}{lcc}
\hline & $\begin{array}{l}\text { Temperature } \\
\left.\mid{ }^{\circ} \mathrm{C}\right)\end{array}$ & $\begin{array}{l}\text { Cell size } \\
\text { at division } \\
(\mu \mathrm{m})\end{array}$ \\
\hline Wild type & 30 & $14.2 \pm 0.3$ \\
cdc25-22 & 26 & $21.9 \pm 0.8$ \\
sty1-1 & 30 & $23.2 \pm 1.6$ \\
sty1-1 pyp1::ura4 pyp2::LEU2 & 30 & $22.9 \pm 2.1$ \\
sty1-1 cdc25-22 & 26 & $\mathrm{cdc}$ \\
sty2-1 & 30 & $23.4 \pm 1.3$ \\
sty2-1 pyp1::ura4 pyp2::LEU2 & 30 & $24.2 \pm 1.3$ \\
sty2-1 cdc25-22 & 26 & $\mathrm{cdc}$ \\
\hline
\end{tabular}

Cell size measurements of septated cells grown in either liquid synthetic minimal medium, (EMM). (cdc) Cell division cycle phenotype. The temperature at which the measurements were made is indicated. Measurements were the mean of 30 individual determinations ( \pm S.D.). 
sty2-1 cells were transformed with a plasmid constitutively expressing either $p y p 1$ or $p y p 2$ from the strong $a d h$ promoter as compared with empty vector alone (data not shown). From this we conclude that the sty1-1 and sty2-1 cells are completely epistatic to control of mitotic initiation by the $p y p 1$ and pyp2 PTPases.

\section{sty2 is allelic to the wis1 MAP kinase kinase}

We noted that mutants in the wis1 gene, which encodes a putative MAP kinase kinase homolog, are delayed in mitotic initiation to a similar extent to the sty1-1 and sty2-1 mutants (Warbrick and Fantes 1991). The relationship of wis1 to sty1 and sty2 was examined. During initial characterization we observed that the growth of single sty1-1 and sty2-1 mutant cells was defective at high temperatures. Neither sty1-1 nor sty2-1 mutant cells were able to grow at $36.5^{\circ} \mathrm{C}$, whereas wild-type cells are unaffected (Fig. 2A). Importantly, sty2-1 but not sty1-1 cells ectopically expressing the wis 1 gene from the thiamine-repressible $n m t 1$ promoter were able to proliferate at the restrictive temperature of $36.5^{\circ} \mathrm{C}$ (Fig. 2B). We find that $\Delta$ wis1 cells are also defective for cell division at $36.5^{\circ} \mathrm{C}$ (Table 2; data not shown). To determine the relationship between sty2 and wis1, sty2-1 cells were crossed to $\Delta$ wis 1 cells. Analysis of $>5000$ spores from this cross revealed no wild-type recombinants, strongly suggesting that sty2 and wis1 are allelic. Supporting this argument a $\Delta$ wis1 $\Delta p y p 1 \Delta p y p 2$ triple mutant strain was found to be viable (data not shown). Because $\Delta$ wis1 cells divide at an identical cell size to the sty2-1 allele, we conclude that sty2-1 harbors a null mutation in the wis1 MAP kinase kinase.

\section{Sty1 encodes a MAP kinase homolog}

We used the observation that sty1-1 cells are unable to proliferate at high temperature to isolate the sty1 gene. A genomic library was introduced into sty1-1 cells, and from a total of 50,000 transformants isolated at $30^{\circ} \mathrm{C}, 6$ were able to divide at $36.5^{\circ} \mathrm{C}$. Plasmids isolated from these six suppressors contain three different inserts that are related by restriction analysis and were subsequently shown to encode the same gene. pSTY1-4 containing the smallest insert is able to fully suppress the temperature sensitivity of a sty1-1 but not a sty2-1 mutant strain (Fig. 2C).

The restriction map of pSTY1-4 was not similar to a number of previously identified mitotic regulators, including cdc25 (Russell and Nurse 1986), wee1 (Russell and Nurse 1987a), nim1 (Russell and Nurse 1987b), wis1 (Warbrick and Fantes 1991), cdc2 (Durkacz et al. 1986), or cdc13 (Fig. 3A; Hagan et al. 1988). The complementing activity of pSTY1-4 was localized by transposon mutagenesis and subcloning analysis (Fig. 3B; Sedgewick and Morgan 1994). Inactivating transposon insertions were used as templates for sequencing, which revealed a single open reading frame (ORF) of $1047 \mathrm{bp}$ capable of encoding a polypeptide of 349 amino acids. The predicted protein sequence was analyzed against current
A
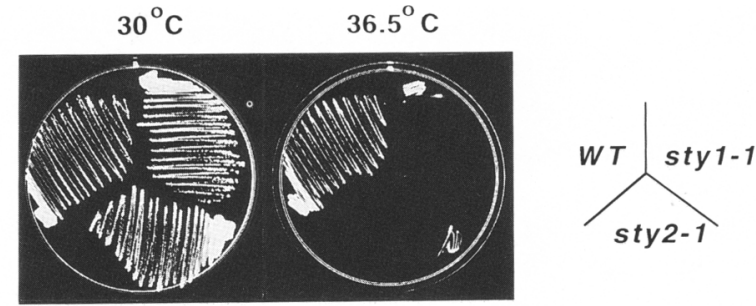

B
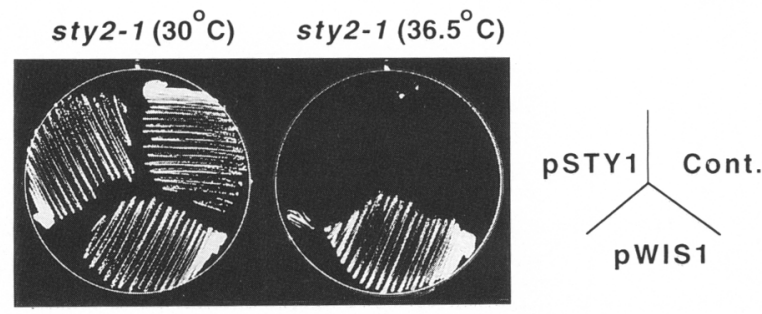

C
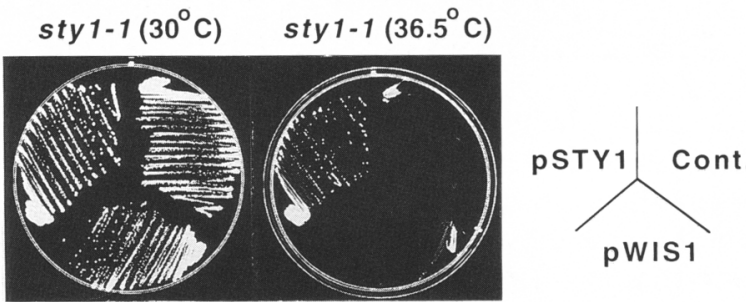

Figure 2. Plasmid complementation of sty1 and sty2 mutants. (A) sty1-1 and sty2-1 mutants are temperature sensitive. Wildtype strain 972 (top left segment), sty1-1 cells (top right segment), and sty2-1 cells (bottom segment) were grown on YEPD and then streaked onto YEPD plates and allowed to grow for 3 days either at $30^{\circ} \mathrm{C}$ (left plate) or $36.5^{\circ} \mathrm{C}$ (right plate). (B,C) Plasmid complementation of sty2-1 and sty1-1 mutants. sty2-1 ura4 $D 18$ cells $(B)$ or sty1-1 ura4-D18 cells $(C)$ were transformed either with the control plasmid pUR19 (Cont.), pSTY14 , a derivative of pUR 19 containing $5.2 \mathrm{~kb}$ of genomic sequence (pSTY1), or a plasmid expressing the wis1 ORF behind the thiamine-repressible nmt1 promoter pREP42-wisl and the $u r a 4^{+}$. selectable marker (pWIS1). Transformants were grown and streaked on minimal medium lacking thiamine and uracil and growth of the cells monitored after 3 days at either $30^{\circ} \mathrm{C}$ (left) or $36.5^{\circ} \mathrm{C}$ (right).

data bases and found to be related most closely to a subfamily of MAP kinases that have been implicated in osmoregulation in budding yeast and stress-activated pathways in human cells (Brewster et al. 1993; Kyriakis et al. 1994; Han et al. 1994; Lee et al. 1994). Specifically, the Styl protein kinase was found to be related most closely to HOG1 from budding yeast ( $86 \%$ identical) and $57 \%$ identical to CSBP1 MAP kinase from human cells (Fig. 4A; Lee et al. 1994) and somewhat more distantly related (between $40 \%$ and $43 \%$ identical) to a family of four stress-activated protein kinases (SAPKs) from rat cells (Kyriakis et al. 1994). All members of the MAP kinase superfamily so far described are activated by dual phosphorylation on two closely spaced residues that are located at residues Thr-171 and Tyr-173 in the Styl pro- 
Table 2. Strains used in this study

\begin{tabular}{|c|c|c|}
\hline Strain no. & Genotype & Reference/source \\
\hline PR 109 & leu1-32 ura4-D18 $\mathrm{h}^{-}$ & $\begin{array}{l}\text { P. Russell (The Scripps Research Institute, } \\
\text { San Diego, CA) }\end{array}$ \\
\hline JM 1093 & leu1-32 ura4-D18 his1-102 $\mathrm{h}^{-}$ & this study \\
\hline GL 193 & leu1-32 ura4-D18 ade6-704 $\mathrm{h}^{-}$ & P. Russell \\
\hline GL 196 & leu1-32 ura4-D18 cdc25-22 $\mathrm{h}^{+}$ & Russell and Nurse (1986) \\
\hline PR 170 & leu1-32 ura4-D18 wee1-50 $\mathrm{h}^{+}$ & Russell and Nurse (1987a) \\
\hline GL 190 & leu1-32 ura4-D18 wee1-50 cdc25::ura4 $h^{+}$ & Russell and Nurse (1986) \\
\hline PR 253 & leu1-32 ura4-D18 pyp1::ura4 $h^{-}$ & Millar et al. $(1992 b)$ \\
\hline JM 1032 & leu1-32 ura4-D18 ade6-704 pyp2::LEU2 $\mathrm{h}^{-}$ & this study \\
\hline JM 1023 & leu1-32 ura4-D18 NMT-pyp1(ura4) $h^{+}$ & this study \\
\hline JM 1036 & leu1-32 ura4-D18 ade6-704 NMT-pyp1(ura4) pyp2::LEU2 $\mathrm{h}^{-}$ & this study \\
\hline JM 1042 & leu1-32 ura4-D18 his1-102 NMT-pyp1(ura4) pyp2::LEU2 $h^{+}$ & this study \\
\hline JM 1144 & leu1-32 ura4-D18 sty1-1 $\mathrm{h}^{-}$ & this study \\
\hline JM 1162 & leu1-32 ura4-D18 sty2-1 $\mathrm{h}^{-}$ & this study \\
\hline JM 1206 & leu1-32 ura4-D18 sty1-1 pyp1::ura4 pyp2::LEU2 & this study \\
\hline JM 1207 & leu1-32 ura4-D18 sty2-1 pyp1::ura4 pyp2::LEU2 & this study \\
\hline JM 1099 & leu1-32 ura4-D18 adh:pyp1(ura4) pyp1 ${ }^{+} h^{-}$ & this study \\
\hline ED 890 & leu1-32 ura4-D18 ade6-M210 wis1::LEU2 $\mathrm{h}^{-}$ & Warbrick and Fantes (1991) \\
\hline JM 544 & leu1-32 ura4-D18 wis $1::$ ura4 $\mathrm{h}^{-}$ & this study \\
\hline JM 1160 & leu1-32 ura4-D18 ade6-216 sty1::ura4 $\mathrm{h}^{-}$ & this study \\
\hline
\end{tabular}

tein. Notably, the residue separating these phosphorylation sites appears to be conserved among members of the MAP kinase subfamilies. In human Erk1 and Erk2 and budding yeast FUS3 and KSS1, this sequence is Thr-GluTyr, whereas in members of the SAP kinase family and INK1, it is Thr-Pro-Tyr; in fission yeast Sty1, budding yeast HOG1, human CSBP1, and murine p38, it is ThrGly-Tyr. A phylogenetic tree compiled by sequence comparison to a number of stress-activated MAP kinases reveals that Styl belongs to the latter subfamily of MAP kinases (Fig. 4B).
To determine the relationship between the sty $1-1 \mathrm{mu}$ tation and the novel MAP kinase encoded by the pSTY1-4 genomic clone, the ORF of pSTY1-4 was interrupted by the $\mathrm{ura}^{+}$gene (Fig. $3 \mathrm{C}$ ). The resulting plasmid pSTY1::ura4 was unable to rescue a sty1-1 mutant. pSTY1::ura4 was linearized with EcoRI and stably integrated into a leu1-32/leu1-32 ura4-D18/ura4-D18 ade6M216/ade6-M210 $h^{+} / h^{-}$diploid strain. Tetrad dissection of asci from heterozygous diploids gave rise to four viable spores on germination that showed a 2:2 segregation of uracil auxotrophs to uracil prototrophs /data not

A

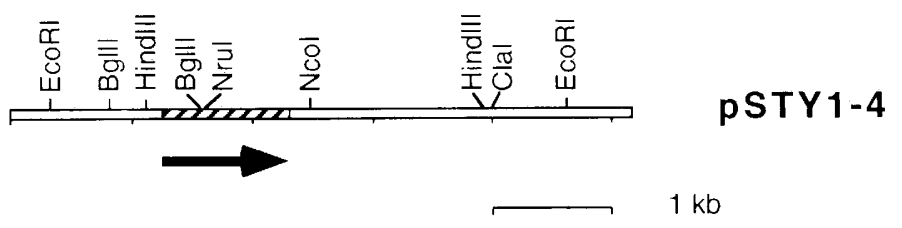

B

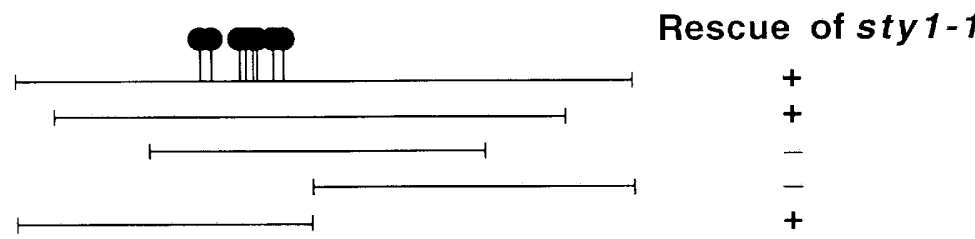

C

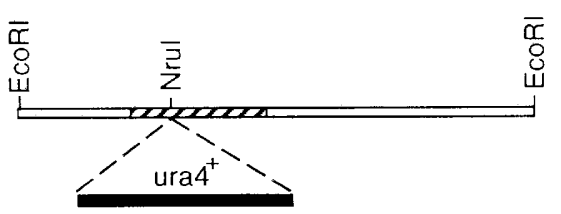

pSTY1::ura4

Figure 3. Restriction map and disruption of sty 1 genomic clone. $(A)$ Restriction map of the insert of pSTY1-4. (Hatched region) The position of the ORF; (arrow) the direction of the ORF, with the arrowhead at the $3^{\prime}$ end of the gene. Intervals of 1 $\mathrm{kb}$ are marked under the map. $\langle B|$ Location of inactivating TnHIS3 transposon insertions and restriction site-based subclones of the pSTY1-4 insert. Functional complementation was tested by transformation into a sty1-1 ura4-D18 strain and the transformants assayed for growth at the restrictive temperature of $36.5^{\circ} \mathrm{C}$. (C) Map of pSTY1::ura4 construction. 
A

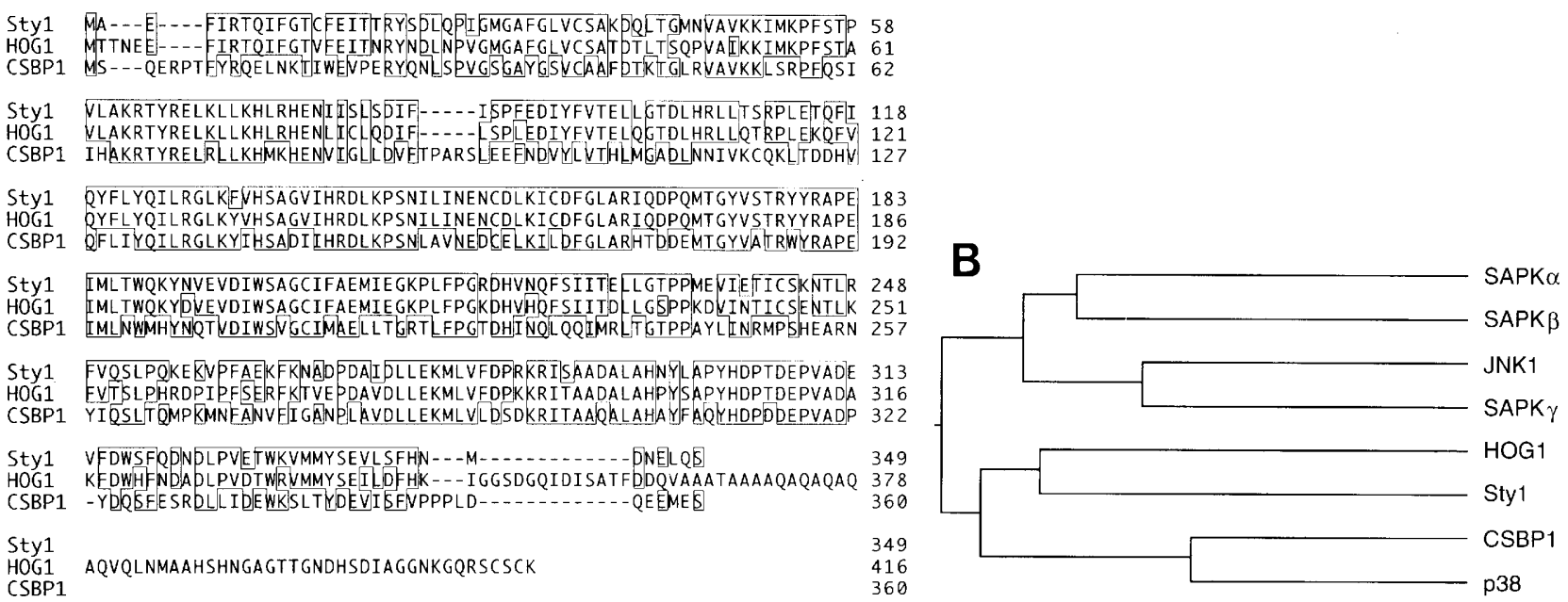

Figure 4. Styl shares homology to osmoregulated MAP kinases. (A) Alignment of the complete Styl amino acid sequence to that of budding yeast HOGl and human CSBP1 MAP kinases. Boxes indicate identities among all three proteins. $(B)$ A phylogenetic tree of amino acid sequence comparison of fission yeast Styl to rat SAPK $\alpha$ II, rat SAPK $\beta$, rat SAPK $\gamma$ (Kyriakis et al. 1994), human JNK1 (Dérijard et al. 1994), budding yeast HOG1 (Brewster et al. 1993), human CSBP1 (Lee et al. 1994), and mouse p38 (Han et al. 1994). Homologies and phylogenetic trees were generated using a MegAlign work package based on a Jotun Hein algorithm (DNASTAR). The nucleotide sequence of the sty1 gene will appear in the EMBL, GenBank, and DDBJ nucleotide sequence data bases under accession number X89262.

shown). All uracil prototrophs were found to be temperature sensitive and elongated relative to wild type to the same extent as the sty1-1 mutation. Random spore analysis of a cross between these uracil prototrophs and sty1-1 cells revealed that of 3000 spores analyzed no wild-type recombinants could be isolated. We conclude that $\Delta$ sty1 cells are viable and that sty1-1 cells harbor a null mutant in a novel MAP kinase. Double mutant $\Delta$ wis1 $\Delta$ sty1 cells were found to be indistinguishable from the single mutants alone, suggesting that the Styl MAP kinase lies on the same signal transduction pathway as the Wisl MAP kinase kinase.

\section{Osmotic stress causes tyrosine phosphorylation of Sty1 and reduces cell size at division}

The striking homology of Styl to the HOG1 MAP kinase from $S$. cerevisiae and of Wisl to the HOG4 MAP kinase kinase prompted us to examine whether $\Delta$ sty 1 cells and $\Delta$ wis1 cells were sensitive to osmotic stress. Neither $\Delta s t y 1$ nor $\Delta$ wis1 mutants were able to proliferate in the presence of $1.5 \mathrm{M}$ sorbitol or $0.8 \mathrm{M} \mathrm{KCl}$ (Fig. $5 \mathrm{~A}$ ), and arrested as highly elongated, branched, and septated cells (data not shown). Wild-type cells continued to proliferate under these conditions (Fig. 5A). These results confirm the previous observation that $\Delta$ wis 1 cells are sensitive to high salt conditions (Shiozaki and Russell 1995) and demonstrate that both sty1 and wis1 are critically required for the cellular response to osmotic stress in fission yeast.

We wished to examine whether Styl bears the hallmark of MAP kinases of being phosphorylated on tyro- sine residues by the action of a MAP kinase kinase. Because initial attempts to identify the Styl protein in whole cell extracts were unsuccessful, an episomal plasmid ectopically expressing a carboxy-terminally tagged version of Styl from a partially defective thiamine-repressible nmt1 promoter was constructed. Log-phase cultures bearing this plasmid were subjected to osmotic stress and the Styl protein affinity precipitated. The phosphorylation state of Styl was assessed by Western blot using a monoclonal antibody to phosphotyrosine. Figure 5B demonstrates that in wild-type cells, the level of phosphotyrosine on the Styl protein increases rapidly after exposure to $0.9 \mathrm{M} \mathrm{KCl}$. Duplicate samples probed using a monoclonal antibody to the hemagglutinin (HA) epitope tag showed that the level of protein did not change through the course of the experiment (Fig. 5B). In all experiments, phosphotyrosine was detectable on the Styl protein, even in minimal medium. Significantly, this basal level of phosphotyrosine was absent in $\Delta$ wis1 cells, and no induction of tyrosine phosphorylation on the Styl protein was observed even on prolonged exposure to osmotic stress (Fig. 5B). These results strongly suggest that Wis 1 is the MAP kinase kinase that tyrosine phosphorylates and activates the Styl MAP kinase in vivo.

From our observation that wis 1 and sty 1 are required for the cellular response to osmotic stress, we hypothesized that cell size at division may be regulated by external osmolarity. To test this prediction, wild-type cells were grown to mid-log phase in rich medium either alone or in the presence of $1 \mathrm{~m}$ sorbitol and cell size at division measured. Although no difference in growth 


\section{A YEPD}

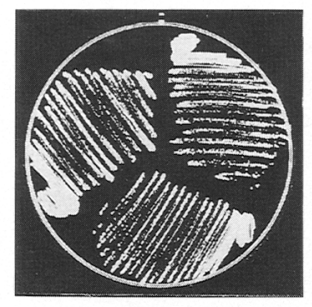

$Y E P D+0.8 \mathrm{M} \mathrm{KCl}$

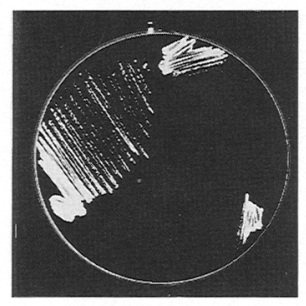

YEPD + 1.5M Sorb.

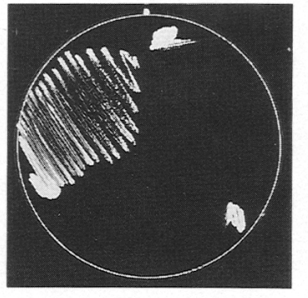

9.

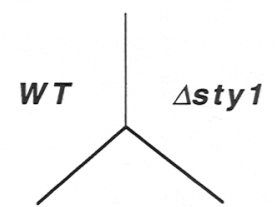

$\Delta$ wis 1
B

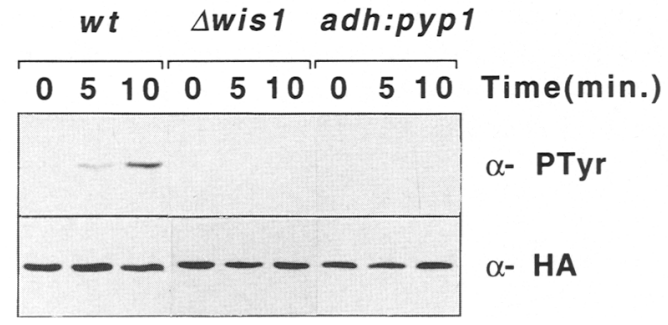

Figure 5. Sty 1 and Wis 1 are members of an osmosensing MAP kinase cascade. $(A)$ Sty 1 and Wis 1 are required for resistance to osmotic stress. Wild type, sty1::ura4 and wis1::LEU2 cells were grown on YEPD plates and then streaked onto either YEPD medium alone (top left), YEPD containing $1.5 \mathrm{M}$ Sorbitol (top right), and YEPD containing $0.8 \mathrm{M} \mathrm{KCl}$ (bottom left) and incubated for 3 days at $30^{\circ} \mathrm{C}$. (Bottom right) The location of each strain on the plates. $(B)$ Osmotic stress induces tyrosine phosphorylation of Sty1. The following strains, leu1-32 ura4-D18 (WT); wis1::ura4 leu1-32ura4-D18 ( $\Delta$ WIS1); adh:pyp1(ura4) leu1-32 ura4-D18 cells (ADH-PYP1), were transformed with pREP41-sty1(HA-6His) and grown at $30^{\circ} \mathrm{C}$ to mid-log phase in minimal medium lacking leucine and in the absence of thiamine to induce overexpression of epitope-tagged sty1 from the thiamine-repressible $n m t 1$ promoter. Cells were then incubated in the same medium containing $0.9 \mathrm{M} \mathrm{KCl}$ for the times indicated. Approximately $2 \times 10^{8}$ cells were harvested and lysed at each time point, and the Styl protein precipitated using $\mathrm{Ni}^{2+}$ NTA agarose. Precipitates were probed by Western blot for the presence of phosphotyrosine ( $\alpha$-pTyr) or HA epitope tag $(\alpha-H A)$.

rate was observed, wild-type cells divide at $11.2 \pm 1.1 \mu \mathrm{m}$ in the presence of sorbitol compared with $14.3 \pm 1.3 \mu \mathrm{m}$ in rich medium alone. In contrast, $\Delta$ wis 1 cells were unable to undergo a reduction in cell size at division in response to a mild osmotic stress, dividing at $18.6 \pm 1.8$ $\mu \mathrm{m}$ in rich medium and $18.4 \pm 2.6 \mu \mathrm{m}$ in rich medium containing $1 \mathrm{M}$ sorbitol. These results are consistent with the conclusion that the sty1 MAP kinase pathway controls cell size at division in response to osmotic stress. It was noted, however, that cell size at division of $\Delta$ wis1 cells is reduced on rich medium as compared with minimal medium, as observed previously (Warbrick and Fantes 1991).

\section{Pyp2 MAP kinase phosphatase is induced} by osmotic stress

The role of pyp1 and pyp2 in the regulation of the sty1 MAP kinase pathway was examined. Overexpression of pyp1 was found to abolish the increase in phosphotyrosine content on the Styl protein induced by osmotic stress (Fig. 5B), raising the possibility that Styl may be a direct substrate for Pyp1 and Pyp2 PTPases. Initial experiments showed that neither the pyp1 nor pyp2 mRNAs are periodically expressed in the cell cycle (data not shown). However, we observed that the pyp 2 mRNA, although low in normal medium, increases dramatically following exposure to $0.9 \mathrm{M} \mathrm{KCl}$, reaching a maximum after $\sim 1 \mathrm{hr}$ and declining to basal levels by $3 \mathrm{hr}$ (Fig. 6A). In contrast, neither $c d c 2$ mRNA (Fig. 6A) nor pyp1 mRNA was altered during the time course of this experiment (data not shown). Similar results were obtained when cells were exposed to medium containing $1.2 \mathrm{M}$ sorbitol (data not shown). Importantly, no induction of pyp2 mRNA was observed in a $\Delta$ wis1 strain (Fig. $6 \mathrm{~A}$ ) or in a sty1-1 mutant (M. Wilkinson and J. Millar, unpubl.), indicating that the sty1 MAP kinase pathway is required for induction of pyp2 mRNA in response to osmotic stress.

These results prompted us to examine whether the tyrosine phosphorylation state of Styl was influenced by pyp2 on prolonged exposure to osmotic stress. In a wildtype strain, the Styl protein was found to be maximally phosphorylated between 15 and $30 \mathrm{~min}$ after exposure to $0.9 \mathrm{M} \mathrm{KCl}$ and declined to basal levels after $\sim 1 \mathrm{hr}$ (Fig. 6B). Notably, the time course of tyrosine dephosphorylation coincides well with the time course of pyp2 mRNA induction (Fig. 6A). To examine whether this dephosphorylation was influenced by $p y p 2$, epitope-tagged Styl was introduced into a $\Delta p y p 2$ strain. In these cells the percentage increase in phosphotyrosine on the Sty 1 protein was only $68 \%$ in three independent experiments after $15 \mathrm{~min}$ of incubation with $0.9 \mathrm{M} \mathrm{KCl}$ compared to $485 \%$ observed in a wild-type strain. In contrast to wild type, Styl remained tyrosine phosphorylated on prolonged exposure to osmotic stress in $\Delta p y p 2$ cells (Fig. 6B). Little difference in the time course of phosphorylation and dephosphorylation was observed in a $\Delta p y p 1$ strain relative to wild type (data not shown). These results suggest that Pyp1 and Pyp2 perform distinct roles in the tyrosine dephosphorylation of Styl and that Pyp2 acts in a feedback pathway to tyrosine dephosphorylate Sty1.

To determine whether the Pyp2 protein could directly influence the phosphorylation state of Styl in vitro, tyrosine-phosphorylated Styl was incubated in the presence of a glutathione $S$-transferase (GST)-Pyp2 fusion 


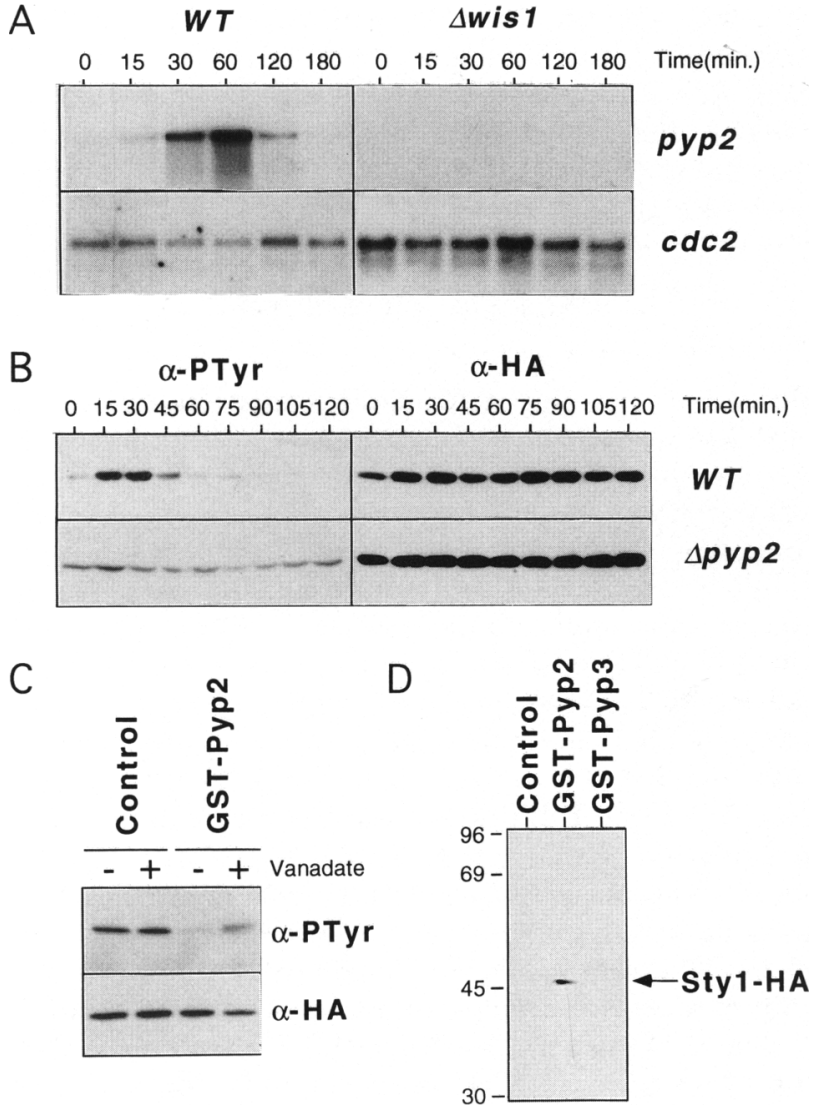

Figure 6. Pyp2 is a MAP kinase phosphatase. (A) Pyp2 mRNA is induced by osmotic stress. Log-phase cultures of either wildtype $(W T)$ or $\Delta$ wis 1 cells were incubated in YEPD containing 0.9 $\mathrm{M} \mathrm{KCl}$ for the times indicated. Total RNA was extracted and probed using DNA specific to the pyp2 or $c d c 2$ genes. $|B|$ Effect of pyp2 on tyrosine phosphorylation of Sty1. Log-phase cultures of leu1-32 ura4-D18 (WT), or pyp2::ura4 leu1-32 ura4-D18

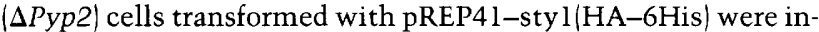
cubated in $0.9 \mathrm{M} \mathrm{KCl}$ for the times indicated. Styl was isolated by $\mathrm{Ni}^{2+}-\mathrm{NTA}$ affinity precipitation and probed by Western blot for the presence of phosphotyrosine ( $\alpha$-PTyr) or HA epitope tag $(\alpha-\mathrm{HA}) .(C)$ Pyp2 PTPase dephosphorylates Sty1 in vitro. Tyrosine-phosphorylated Styl protein was isolated by affinity precipitation from osmotically stressed wild-type cells expressing epitope-tagged Styl. Beads were incubated either in the presence $(+)$ or absence $(-)$ of $2 \mathrm{~mm}$ orthovanadate and either no protein (Control) or $10 \mu \mathrm{g}$ of GST-Pyp2 fusion protein or $10 \mu \mathrm{g}$ of GST-Pyp3 fusion protein for $30 \mathrm{~min}$ at $30^{\circ} \mathrm{C}$. Styl was then probed by Western blot for the presence of phosphotyrosine $(\alpha-$ PTyr) or HA epitope tag ( $\alpha-\mathrm{HA}) .(D)$ Pyp2 associates with the Sty1 MAP kinase. Cell lysates containing epitope-tagged Styl were incubated in the presence of no protein (Control), $10 \mu \mathrm{g}$ of GST-Pyp2 fusion protein, or $10 \mu \mathrm{g}$ of GST-Pyp3 fusion protein for $1 \mathrm{hr}$ at $4^{\circ} \mathrm{C}$. After this time proteins were precipitated on glutathione-agarose beads, washed three times with lysis buffer, and probed for the presence of Styl using a monoclonal antibody to the HA epitope tag.

protein containing the carboxy-terminal catalytic 303 amino acids of the Pyp2 protein (Millar et al. 1992b). As the results in Figure 6C demonstrate, GST-Pyp2 was able to reduce the level of phosphotyrosine on Styl by $\sim 90 \%$. Dephosphorylation by GST-Pyp2 was greatly inhibited by vanadate, a general PTPase inhibitor (Fig. 6C). During these experiments we noted that the Pyp2 PTPase forms a weak but specific association with Styl. Lysates containing epitope-tagged Styl were incubated in the presence of either GST-Pyp2 or an equivalent concentration of a functionally unrelated PTPase fusion protein, GST-Pyp3 (Millar et al. 1992a). The results in Figure 6D illustrate that epitope-tagged Sty1 specifically coprecipitates with GST-Pyp2, whereas no association with GST-Pyp3 was observed. Together, these data indicate that Pyp2 is a MAP kinase phosphatase that acts in a feedback loop to inactivate Styl following exposure to osmotic stress (Fig. 7).

\section{Discussion}

Protein modification by tyrosine phosphorylation, although relatively common in the control of proliferation, differentiation, and intercellular communication between mammalian cells, is rare in yeast. Only recently has the discovery of a number of tyrosine phosphatases in fission yeast revealed an important role for tyrosine phosphorylation in cellular growth control of unicellular eucaryotes. This study was initiated to uncover the mechanism of action of two tyrosine-specific phos-

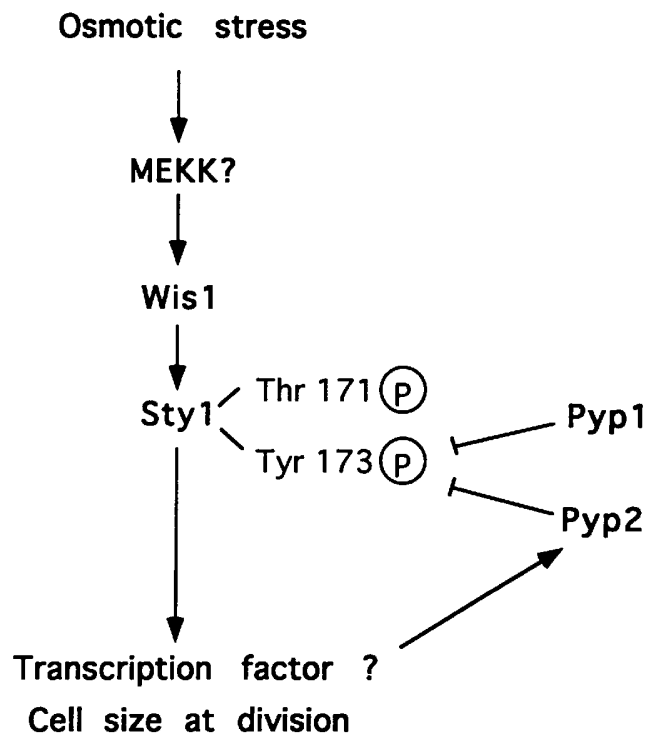

Figure 7. Osmotic control in fission yeast. This model depicts the genetic and biochemical interactions described in this paper. Osmotic stress induces activation of Wis1 by an as-yetunidentified MAP kinase kinase kinase (or MEKK). This leads to dual phosphorylation of Sty1 on residues Thr-171 and Tyr-173 to induce its activation. Activation of Styl leads to an advancement in the timing of mitosis and a reduction in cell size at division. We propose a feedback loop by which activation of Styl leads to accumulation of the pyp 2 mRNA presumably through the action of an unidentified transcription factor, which in turn leads to dephosphorylation of Styl and its inactivation. The phosphatases that dephosphorylate Thr-171 on the Styl protein have not been identified. 
phatases, pyp1 and pyp2, shown previously to act as inhibitors of mitotic initiation in fission yeast and to share an essential overlapping function (Millar et al. 1992b; Ottilie et al. 1992). We examined the mechanism underlying this loss of viability by isolating spontaneous mutations that could bypass the requirement for $p y p 1$ and pyp2.

Sty1 and Wis1 are required for the cellular response to osmotic stress

We have isolated mutations in two complementation groups that define a MAP kinase signaling pathway controlling cell size at division in fission yeast. We have identified the central members of this pathway as the Wis 1 MAP kinase kinase and Styl MAP kinase. We present evidence that the Pyp1 and Pyp2 PTPases function in opposition to the Wisl MAP kinase kinase to control tyrosine phosphorylation and, presumably, activity of the Styl MAP kinase. Sequence analysis reveals that Styl is closely related to a subfamily of MAP kinases that have been implicated in osmoregulation in both budding yeast and mammalian cells (Brewster et al. 1993; Han et al. 1994; Lee et al. 1994). We demonstrate that the sty1 and wis1 genes are themselves required for osmoregulation in fission yeast by virtue of the observations that, first, cells bearing deletions of either gene are sensitive to a number of independent osmotic stresses, and second, Sty1 is tyrosine phosphorylated following osmotic stress in a manner dependent on the wis1 MAP kinase kinase. Thus, Styl is a structural and functional homolog of budding yeast HOG1, and Wis1 is the MAP kinase kinase that tyrosine phosphorylates and activates Styl in vivo. Because no prior assumptions were made as to the function of $p y p 1$ and $p y p 2$, we note that it was fortuitous that the suppression screen in this study was performed in the presence of $1 \mathrm{M}$ sorbitol in which sty ${ }^{-}$ and wis $1^{-}$mutants are viable, and not in the presence of $1.5 \mathrm{M}$ sorbitol, conditions under which they are unable to continue proliferating.

\section{Loss of pyp 1 and pyp 2 causes hyperactivation of Sty1}

Simultaneous inactivation of pyp 1 and pyp 2 causes aberrant cellular morphology and growth arrest. Several lines of evidence suggest that this is because of hyperactivation of the Styl MAP kinase. First, the synthetic lethality of a $\Delta p y p 1 \Delta p y p 2$ double mutant is suppressed by a mutation in either the sty 1 or wis1 genes. Second, strong overexpression of the wis1 MAP kinase kinase from the thiamine-repressible nmt1 promoter is lethal and exhibits a terminal phenotype indistinguishable from the conditional NMT-pyp1 $\triangle p y p 2$ cells, an effect that is not observed in a sty 1-1 mutant or in a strain constitutively overexpressing the pyp1 PTPase (J.-C. Shieh and J.B.A. Millar, unpubl.). The mechanism by which hyperactivation of the Styl kinase causes a loss of normal cell morphology and growth arrest is uncertain at present. Hyperactivation of Sty 1 may lead to a lethal increase in intracellular osmolarity such that cells eventually die by lysis. Alternatively, the Styl MAP kinase pathway may directly control cell polarity. We are attempting to distinguish between these possibilities. Recent evidence that correct positioning of the actin cytoskeleton in $S$. cerevisiae after osmotic stress requires the activity of the HOG1 MAP kinase supports the latter model (Brewster and Gustin 1994). Intriguingly, activation of a close homolog of Styl in rat PC12 cells leads to phosphorylation of Hsp27, a small heat shock protein implicated in actin filament stability (Lavoie et al. 1993; Rouse et al. 1994).

\section{Distinct roles for the Pyp1 and Pyp2 MAP kinase phosphatases}

The genetic data in this paper strongly suggest that both the Pypl and Pyp2 PTPases inhibit the sty1 MAP kinase pathway. This conclusion is supported by the observation that both the Pyp1 and Pyp2 PTPase influence the tyrosine phosphorylation state of Styl in vivo and that the Pyp2 PTPase associates with and tyrosine dephosphorylates Styl in vitro. In particular, we observe that the dephosphorylation of Styl on prolonged exposure to osmotic stress is partially defective in a $\Delta p y p 2$ strain. We find that the pyp2 mRNA is induced strongly under these conditions, indicating that Pyp2 acts in a feedback loop to dephosphorylate Styl. Notably, the mRNAs for a number of dual-specificity MAP kinase phosphatases are induced by extracellular stimulation, including human MKP1, CL100, PAC1, and budding yeast MSG5, although the mechanism of induction is not known (Keyse and Emslie 1992; Sun et al. 1993; Doi et al. 1994; Ward et al. 1994). We demonstrate that both wis1 and sty1 are required for induction of pyp 2 mRNA, presumably via the action of an as-yet-unidentified transcription factor. Notably, some dephosphorylation of Styl was observed consistently in a $\Delta p y p 2$ strain indicating the existence for other mechanisms of Sty 1 inactivation. In contrast to pyp2, the pyp1 mRNA is not induced by osmotic stress indicating that Pyp1 and Pyp2 PTPases perform distinct roles as MAP kinase phosphatases for Styl. The precise role of Pypl in Styl dephosphorylation is under further investigation.

Because Pyp1 and Pyp2 PTPases are specific for tyrosine residues, these data also suggest that two distinct classes of MAP kinase phosphatase act to dephosphorylate residues Thr-171 and Tyr-173 in the Styl protein. Pertinent to this, mutations that bypass the lethal combination of the deletion of two type $2 \mathrm{C}$ phosphatases ptc1 and ptc3 in fission yeast have been found to reside in the wis1 MAP kinase kinase and a second locus, $s p c 1$ (Shiozaki and Russell 1995). Sequence comparison revealed that $s p c 1$ and sty 1 are the same gene, indicating a role for type $2 \mathrm{C}$ serine/threonine phosphatases in the inactivation of this pathway $(K$. Shiozaki and $P$. Russell, pers. comm.). Similarly, Maeda and colleagues have demonstrated that overexpression of a tyrosine-specific phosphatase, PTP2, or two serine/threonine-specific type $2 \mathrm{C}$ phosphatases, PTC1 and PTC3, reverse 
hyperactivation of the HOG1 MAP kinase pathway caused by inactivation of the SLN1 gene (see below); however the targets of these phosphatases have not been established (Maeda et al. 1994). Further experimentation will be required to determine the nature of the phosphatases regulating Thr-173 phosphorylation on the Styl protein.

\section{An osmosensing MAP kinase pathway controlling} cell size at division

The pyp1 and pyp2 PTPases have been implicated in the control of mitotic initiation in fission yeast on the basis of their effects on cell size at division (Millar et al. 1992b; Ottilie et al. 1992). In this study we demonstrate that pyp1 and pyp2 mediate control of cell size at division by dephosphorylating Styl and act in opposition to the wis1 MAP kinase kinase. Notably the wis1 gene was initially described as a dose-dependent initiator of mitosis (Warbrick and Fantes 1991). We show that loss of sty1 delays the timing of mitotic initiation. We demonstrate further that wis1 and sty1 are required for the cellular response to osmotic stress and that chronic exposure to osmotic stress causes a reduction in cell size at division. These results strongly support the conclusion that the sty1 MAP kinase pathway regulates cell size at division in response to changes in external osmolarity, thus revealing a potentially vital link between the detection of environmental stress and control of the cell cycle.

Physiological and genetic studies indicate that the initiation of mitosis in fission yeast requires attainment of a critical cell mass (Nurse 1975; Fantes and Nurse 1977). Thus, mutations that alter the timing of mitosis uncouple size control from cell cycle progression. In principle, the sty1 MAP kinase pathway may also alter mass control over the initiation of mitosis by impinging on the activity of the $c d c 2$ kinase. An alternative explanation is that osmotic stress and activation of the sty1 MAP kinase pathway do not alter cell size control governing the initiation of mitosis but lead to an increase in intracellular density, for example, by an increase in intracellular glycerol concentration. To maintain mass control over the initiation of mitosis, cells undergo a reduction in cell volume. Because $S$. pombe cells grow by length extension this would be expressed as a reduction in cell size at division. Further experimentation will be required to determine which of these hypotheses is correct and to elucidate the molecular basis underlying this response. It has been known for some time that exposure of human cells to anisotonic media initiates a response that regulates cellular volume (Grinstein and Foskett 1990). Furthermore, it is now recognized that osmotic stress activates a number of MAP kinases including JNK1 and p38 in mammalian cells that share extensive sequence homology to Styl (Galcheva-Gargova et al. 1994; Han et al. 1994), raising the possibility that the mechanisms controlling eucaryotic cell size may be evolutionarily conserved.

\section{A role for the Sty1 MAP kinase pathway in stationary phase?}

Previous data have demonstrated that mutants in the wis1 MAP kinase kinase rapidly lose viability in stationary phase suggesting that this pathway is influenced by nutritional stimuli (Warbrick and Fantes 1991). Cells overexpressing the pyp1 PTPase and $\Delta$ sty 1 cells exhibit the same phenotype, indicating that the sty1 MAP kinase may be activated on exit from the cell cycle (J.B.A. Millar, unpubl.). The nature of the signal that might activate the pathway upon entry into stationary phase is at present unclear, though we believe this is unlikely to be attributable to changes in external osmolarity of the medium. Unlike sty1 and wis1, no defect in cell size at division, long-term survival in stationary phase or sensitivity to growth at high temperature has been ascribed to budding yeast bearing mutations in the HOG1 and HOG4 gene (Brewster et al. 1993). Furthermore, wis1 does not complement a HOG4 mutation nor vice versa, suggesting a possible evolutionary divergence between these two yeasts. It is intriguing that the mouse p38 MAP kinase is activated not only by osmotic stress but also by ultraviolet light, heat shock, bacterial endotoxic lipopolysaccharide (LPS), and stress related pro-inflammatory cytokines such as tumor necrosis factor $\alpha$ (TNF $\alpha)$ and interleukin-1 (Il-1) (Freshney et al. 1994; Han et al. 1994; Rouse et al. 1994; Dérijard et al. 1995), demonstrating that more than one stimulus can modulate the activity of this pathway in metazoa. It will be of great interest to determine the range of extracellular signals, other than osmotic stress, that control the sty1 MAP kinase pathway in fission yeast and to what extent this pathway is evolutionarily conserved.

The activity of MAP kinase kinases is stimulated via phosphorylation by a MAP kinase kinase kinase (for review, see Herskowitz 1995; Marshall 1994). In the genetic suppression screen performed in this study, only two complementation groups were identified that were viable in the absence of thiamine. This may indicate a functional redundancy in the action of upstream regulators of wis1 or that mutations in such genes are lethal. Notably a set of mutants, which were lethal in the absence of thiamine, were isolated in the same screen and may include mutants in such upstream regulators. These are now the subject of further investigation. In budding yeast, a two-component system consisting of the SLN1 and SSK1 genes has been shown to regulate the HOG1 MAP kinase (Maeda et al. 1994), raising the exciting possibility that a similar system may control the sty1 MAP kinase in fission yeast and possibly higher eukaryotes.

In conclusion, we have identified a conserved MAP kinase pathway in fission yeast that coordinates the cellular response to environmental stress with control of cell size at division. Recently, it has become apparent that stress-activated MAP kinase pathways may play an important role in a variey of physiological and pathological responses in mammals, including inflammation and tumor suppression. The closest human homolog to Sty1, CSBP1, has been shown to be the target of a group of 
synthetic drugs that not only suppress accumulation of the stress related pro-inflammatory cytokines, TNF $\alpha$ and Il-1, but also act as potent therapeutic agents in a number of animal models of chronic and acute inflammation (Lee et al. 1994). We contend that further genetic dissection of the sty1 MAP kinase pathway will advance our understanding of the mechanisms governing the cellular response to environmental stress, and provide an ideal model system with which to study these novel MAP kinase pathways in human cells.

\section{Materials and methods}

\section{Media and general techniques}

Media and genetic methods for studying fission yeast have been reviewed recently (Moreno et al. 1991). General DNA methods were performed using standard techniques (Sambrook et al. 1989). Cell length measurements were made using log-phase cells with a Nikon filar eyepiece drum micrometer at $1200 \times$ magnification. Transformations were regularly performed by lithium acetate method (Moreno et al. 1991) or by electroporation (Prentice 1991) using a Bio-Rad Gene Pulser.

\section{Construction of NMT-pypl(ura4) and pyp2::LEU2 alleles}

The pyp1 ORF was cloned by PCR amplification from an $S$. pombe cDNA library. The 5' oligonucleotide, CCGGATCCATATGAATTTTTCAAACGGTTCAAA, incorporating BamHI and NdeI sites (shown italicized) hybridized to sequences surrounding the ATG initiation codon, whereas the $3^{\prime}$ oligonucleotide, CCGGATCCTCATGTTAAAACCGGGAAATGAAC, incorporating a BamHI site (shown italicized) hybridized to sequences surrounding the TGA termination codon. PCR amplification generated a $1.7-\mathrm{kb}$ fragment that was cleaved with $\mathrm{NdeI}$ and $B a m H I$ and cloned into the NdeI and BamHI sites of pREP82 (Maundrell 1993) containing the thiamine-repressible nmt1 promoter to form pREP82-pyp1. A 1.2-kb fragment containing the ars1 autonomously replicating element was excised by digestion with EcoRI followed by self-ligation. The carboxyterminal half of pyp1 containing the PTPase catalytic domain was removed by digestion with SacI to drop out a 692-bp fragment followed by self-ligation to form pRIP82-pyp1(T). The NMT-pyp1 strain was created by linearizing pRIP82-pyp $1(\mathrm{~T})$ using the unique Sall site in pyp1 and introduced into a leu1-32 ura4 $D 18 h^{-}$strain by lithium acetate transformation onto minimal medium lacking uracil. Stable integrants were identified and verified by Southern blot hybridization.

To create the pyp2::LEU2 allele a $5.1-\mathrm{kb}$ fragment from pGEM-3Z-pyp2 (Millar et al. 1992b) was excised with EcoRI and ligated into the EcoRI site of pBluescript to form pBSSKpyp2. A $2.2-\mathrm{kb}$ fragment containing LEU2 was excised from pREP1 with HindIII, blunt ended with the DNA polymerase I, and ligated into pBSSK-pyp2 that had been digested with $\mathrm{HpaI}$ and $\mathrm{NruI}$ to excise a 1515-bp fragment containing much of the pyp2 ORF to form pBSSK-pyp2::LEU2. The disrupted pyp2 sequence was excised from pBSSK-pyp2::LEU2 with PstI and HindIII and introduced into a leu1-32 ura4-D18 ade6-704 $\mathrm{h}^{-}$strain using lithium acetate transformation onto minimal media plates lacking leucine. Stable integrants were isolated and confirmed by Southern blot hybridization.

\section{Isolation of spontaneous suppressors of NMT-pyp1}

Two strains, JM1036 and JM1042, bearing the NMT-pyp1 $\Delta p y p 2$ alleles were grown to stationary phase in minimal me- dium. Approximately $10^{7}$ cells in two independent screens were plated onto 20 YEPD plates containing $1 \mathrm{M}$ sorbitol and $10 \mu \mathrm{m}$ of thiamine and allowed to incubate for 3 days at $30^{\circ} \mathrm{C}$.

\section{Isolation of the styl genomic clone}

A genomic library, pURB1 (Barbet et al. 1992), was introduced into sty1-1 leu1-32 ura4-D18 $\mathrm{h}^{-}$strain by electroporation and plated on medium lacking uracil. A total of 55,000 transformants were screened. Transformants were replica plated twice to $36.5^{\circ} \mathrm{C}$. Six complementing colonies were identified. Plasmids from these six individual colonies were transformed into DH5 $\alpha$. Three independent plasmids related by restriction map were identified and contained overlapping sequences. pSTY1-1 and pSTY $1-5$ contain a $11.5-\mathrm{kb}$ insert. pSTY1-2 contains a 7.5$\mathrm{kb}$ insert. pSTY1-3, pSTY1-4, and pSTY1-6 contain a 5.2-kb insert. pSTY1-4 was used for further analysis.

\section{Localization and sequencing of the styl gene}

Simultaneous localization and sequencing was performed by transposon mutagenesis of the pSTY1-4 genomic clone using TnHIS3 as described previously (Sedgewick and Morgan 1994). Complementing activity was tested by transformation into a sty1-1 ura4-D18 strain and assayed for growth at $36.5^{\circ} \mathrm{C}$. Dideoxy sequencing was performed using a $\mathrm{T} 7$ sequencing kit from Pharmacia using primers described previously to the $5^{\prime}$ and $3^{\prime}$ ends of the transposon.

\section{Construction of sty1::ura4 allele}

An EcoRI fragment from pSTY1-4 was subcloned into the EcoRI site of pBluescript to form pBSSK-STY1. Plasmid pBSSK-STY1 was digested with $\mathrm{NruI}$ and a $1.6-\mathrm{kb}$ fragment containing the $\mathrm{ura}^{+}$gene ligated into this site after digestion of pREPl with HindIII followed by blunt ending using the large fragment of DNA polymerase I to form pBSSK-STY1::ura4. pBSSKstyl::ura4 was linearized with EcoRI and transformed into a leu1-32/leu1-32 ade6-210/ade6-216 ura4-D18/ura4-D18 $\mathrm{h}^{-} /$ $h^{+}$strain. Stable integrants were selected on medium lacking uracil and genomic DNA subjected to Southern blot hybridization using a sty1-specific probe. Colonies bearing a disruption of sty1 were plated onto minimal medium containing adenine to induce sporulation. The resulting asci were used for tetrad dissection, and the resulting haploid uracil prototrophs were confirmed to bear a disrupted copy of sty1 by genomic Southern blot analysis.

\section{Overexpression of sty1}

The sty 1 cDNA was amplified from the genomic clone pSTY1-4 by PCR amplification. The $5^{\prime}$ oligonucleotide, ATATCTAGAGAATTCATATGGCAGAATTTATTCGTACACAA, incorporating $X b a \mathrm{I}, E c o R I$, and NdeI sites (shown italicized), hybridized to sequences surrounding the ATG initiation codon, whereas the 3' oligonucleotide, TATGCGGCCGCGGGATTGCAGTTCATTATCCA, incorporating a NotI site /shown italicized), hybridised to sequences prior to the TGA termination codon. PCR amplification generated a 1072-nucleotide fragment that was cleaved with NdeI and NotI and cloned into pREP41 (HA-6His) (J. Millar, unpubl.) to form pREP4l-styl (HA-6His), which expresses sty1 under the control of a partially crippled version of the $n m t 1$ thiamine-repressible promoter (Basi et al. 1993). pREP41-sty1(HA-6His) was used to transformed strains bearing the leu1-32 mutation and leucine prototrophs selected. The phenotype of overexpression was deter- 
mined after at least $48 \mathrm{hr}$ growth in the absence of thiamine. The pREP4l-sty1(HA-6His) plasmid was found to rescue the temperature sensitivity of a sty1-1 leu1-32 ura4-D18 strain when grown in the absence of thiamine.

\section{Detection of Sty1 protein}

The Styl protein was partially purified from cells containing the pREP41-sty1(HA-6His) plasmid (see above), which expresses a fusion protein of Styl to a HA peptide epitope and a six histidine carboxy-terminal tail. Briefly, pelleted cells were lysed into lysis buffer $10.5 \%$ NP-40, $0.5 \%$ Na-deoxycholate, $50 \mathrm{~mm} \mathrm{NaF}$, $10 \%$ glycerol, $2 \mathrm{~mm} \mathrm{Na-orthovanadate,} 10 \mathrm{~mm} \beta$-mercaptoethanol, $10 \mu \mathrm{g} / \mathrm{ml}$ of aprotonin, $10 \mu \mathrm{g} / \mathrm{ml}$ of benzamidine, $2 \mathrm{~mm}$ PMSF, $10 \mu \mathrm{g} / \mathrm{ml}$ of pepstatin A, $10 \mu \mathrm{g} / \mathrm{ml}$ of leupeptin, $50 \mathrm{~mm}$ Tris- $\mathrm{HCl}$ at $\mathrm{pH} \mathrm{7.4)} \mathrm{and} \mathrm{the} \mathrm{Styl} \mathrm{protein} \mathrm{isolated} \mathrm{by} \mathrm{affinity}$ precipitation on $\mathrm{Ni}^{2+}-\mathrm{NTA}$ beads (Qiagen). Precipitated proteins were resolved by SDS-PAGE and transfered electrophoretically to nitrocellulose membranes. Membranes were probed with either a monoclonal antibody to the HA epitope (12CA5) or with monoclonal antibody to phosphotyrosine (4G10, UBI). Detection was performed using peroxidase-conjugated antimouse IgGs (Amersham, UK) and chemiluminescence visualization (ECL, Amersham) according to the manufacturer's instructions.

\section{Phosphatase assay}

GST-Pyp2 and GST-Pyp3 fusion proteins were made in Escherichia coli as described previously (Millar et al. 1992a,b) Phosphatase assays were performed in phosphatase buffer $(1 \mathrm{mM}$ EDTA, $2 \mathrm{~mm}$ DTT, $200 \mathrm{~mm}$ imidazole at $\mathrm{pH} 7.2)$ as described previously (Millar et al. 1991).

\section{Construction of wis $1:$ ura4 allele}

The wis1 gene was cloned by PCR amplification from an $S$. pombe cDNA library. The 5' oligonucleotide, CCCCTCGAGCATATGTCTAGATCTTCTCCAAATAATCAACCC, incorporating $X h o I, N d e I, X b a I$, and $B g l I I$ sites (shown italicized), hybridized to sequences surrounding the ATG initiation codon, whereas the 3' oligonucleotide, CACTGCAGCGGCCGCTTCTTTTTTCACCTTTC, incorporating a PstI and NotI site (shown italicized), hybridized to sequences surrounding the TGA termination codon. PCR amplification generated a 1846nucleotide fragment that was cleaved with PStI and XhoI and cloned into the PstI and XhoI sites in pBluescript to form pBSSK-wis1. This plasmid was cleaved with HindIII, and a 1.66$\mathrm{kb}$ HindIII fragment containing the $S$. pombe $u r a 4^{+}$gene was ligated into this site to form pBSSK-wis $1:$ :ura4. Plasmid $\mathrm{pB}$ SSK-wis1::ura4 was cleaved with $P$ stI and $X h o I$ and used to transform a leu1-32 ura4-D18 $\mathrm{h}^{-}$strain. Stable uracil prototrophs were selected. Confirmation of the wis1::ura4 disruption was determined by PCR amplification using the oligonucleotides described above.

\section{Overexpression of wisl}

The wis1 ORF was amplified by PCR using the oligonucleotides described above and cleaved with NdeI and NotI and ligated into the NdeI and NotI sites of pREP42 (HA-6His) (J. Millar, unpubl.) to form pREP42-wis1 (HA-6His). This plasmid was used to transform strains bearing the ura4-D18 mutation and uracil prototrophs selected. The phenotype of overexpression was determined after at least $48 \mathrm{hr}$ growth in the absence of thiamine.

\section{DNA and RNA isolation and hybridization}

$S$. pombe cells were cultured in YEA medium $10.5 \%$ yeast extract, $3 \%$ glucose, $50 \mathrm{mg} /$ liter of adenine) to stationary phase. Chromosomal DNA isolated from a $10-\mathrm{ml}$ culture was dissolved in $25 \mathrm{ml}$ of TE, of which one-fifth was digested with HindIII and subjected to electrophoresis and Southern blot hybridization. A BgIII fragment isolated from the pSTY1-4 gene containing sty1 sequence was radioactively labeled and used as a probe. To isolate RNA, S. pombe cells were cultured in YEPD to exponentially growing phase. Approximately $10 \mu \mathrm{g}$ of total RNA was isolated and resolved by agarose gel electrophoresis and transferred to nitrocellulose for hybridization as described previously (Aves et al. 1985 ). A 1-kb EcoRV fragment from pGEM-3Z-pyp2 was used to probe for pyp2 mRNA. A 1-kb NdeI-BamHI fragment from pREP1-cdc2 (HA-6His) was used to probe for $c d c 2$ mRNA.

\section{Acknowledgments}

We gratefully acknowledge the technical assistance of Odile Mondesert. We thank Lee Johnston, Steve Sedgewick, and members of the Division of Yeast Genetics for helpful advice, discussions, and critical reading of the manuscript. We also thank Paul Russell, Kasuhiro Shiozaki, and Peter Fantes for strains and communicating results prior to publication. This research was supported by the Medical Research Council (MRC).

The publication costs of this article were defrayed in part by payment of page charges. This article must therefore be hereby marked "advertisement" in accordance with 18 USC section 1734 solely to indicate this fact.

\section{References}

Alessi, D.R., C. Smythe, and S.M. Keyse. 1993. The human CL100 gene encodes a Tyr/Thr-protein phosphatase which potently and specifically inactivates MAP kinase and suppresses its activation by oncogenic ras in Xenopus oocyte extracts. Oncogene 8: 2015-2020.

Ammerer, G. 1994. Sex, stress and integrity: the importance of MAP kinases in yeast. Curr. Opin. Genet. Dev. 4: 90-95.

Aves, S.J., B.W. Durkacz, A. Carr, and P. Nurse. 1985. Cloning, sequencing and transcriptional control of the Schizosaccharomyces pombe cdc10 "start" gene. EMBO J. 4: 457-463.

Barbet, N., W.J. Muriel, and A.M. Carr. 1992. Versatile shuttle vectors and genomic libraries for use with Schizosaccharomyces pombe. Gene 114: 59-66.

Basi, G., E. Schmid, and K. Maundrell. 1993. TATA box mutations in the Schizosaccharomyces pombe nmt1 promoter affect transcriptional efficiency but not the transcription start point or thiamine repressibility. Gene 123: 131-136.

Brewster, J.L. and M.C. Gustin. 1994. Positioning of cell growth and division after osmotic stress requires a MAP kinase pathway. Yeast 10: 425-439.

Brewster, J.L., T. de Valoir, N.D. Dwyer, E. Winter, and M.C. Gustin. 1993. An osmosensing signal transduction pathway in yeast. Science 259: 1760-1763.

Coleman T.R., Z. Tang, and W.G. Dunphy. 1993. Negative regulation of the wee 1 protein kinase by direct action of the nim1/cdr1 mitotic inducer. Cell 72: 919-929.

Davis, R.J. 1994. MAPKs: New JNK expands the group. Trends Biochem. 19: 470-473.

Dérijard, B., M. Hibi, I.-H. Wu, T. Barrett, B. Su, T. Deng, M. Karin, and R.J. Davis. 1994. JNK1: A protein kinase stimu- 
lated by UV light and Ha-Ras that binds and phosphorylates the c-jun activation domain. Cell 76: 1025-1037.

Dérijard, B., J. Raingeaud, T. Barrett, I.-H. Wu, J. Han, R.J. Ulevitch, and R.J. Davis. 1995. Independent human MAP kinase signal transduction pathways defined by MEK and MKK isoforms. Science 267: 682-685.

Doi, K., A. Gartner, G. Ammerer, B. Errede, H. Shinkawa, K. Sugimoto, and K. Matsumoto. 1994. MSG5, a novel protein phosphatase promotes adaptation to pheromone response in S. cerevisiae. EMBO I. 13: 61-70.

Durkacz, B., A. Carr, and P. Nurse. 1986. Transcription of the cdc2 ${ }^{+}$cell cycle control gene of the fission yeast Schizosaccharomyces pombe. EMBO J. 5: 369-373.

Fantes, P. and P. Nurse. 1977. Control of cell size at division in fission yeast by a growth-modulated size control over nuclear division Exp. Cell Res. 107: 377-386.

Freshney, N.W., L. Rawlinson, F. Guesdon, E. Jones, S. Cowley, J. Hsuan, and J. Saklatvala. 1994. Interleukin-1 activates a novel protein kinase cascade that results in the phosphorylation of hsp27. Cell 78: 1039-1049.

Galcheva-Gargova, Z., B. Dérijard, I.-H. Wu, and R.J. Davis. 1994. An osmosensing signal transduction pathway in mammalian cells. Science 265: 806-808.

Grinstein, S. and J.K. Foskett. 1990. Ionic mechanisms of cell volume regulation in leukocytes. Annu. Rev. Physiol. 52: 399-414.

Hagan, I.M., J. Hayles, and P. Nurse. 1988. Cloning and sequencing of the cyclin-related $\mathrm{cdc} 13^{+}$gene and a cytologial study of its role in fission yeast mitosis. I. Cell Sci. 91: 587-595.

Han, J., J.-D. Lee, L. Bibbs, and R.J. Ulevitch. 1994. A MAP kinase targeted by endotoxin and hyperosmolarity in mammalian cells. Science 265: 808-811.

Herskowitz, I. 1995. MAP kinase pathways in yeast: For mating and more. Cell 80: 187-197.

Keyse, S.M. and E.A. Emslie. 1992. Oxidative stress and heat shock induce a human gene encoding a protein-tyrosine phosphatase. Nature 359: 644-647.

Kyriakis, J.M., P. Baneriee, E. Nikolakaki, T. Dai, E.A. Rubie, M.F. Ahmad, J. Avruch, and J.R. Woodgett. 1994. The stressactivated protein kinase family of c-jun kinases. Nature 369: 156-160.

Lavoie, J.N., E. Hickey, L.A. Weber, and J. Landry. 1993. Modulation of actin microfilament dynamics and fluid phase pinocytosis by phosphoryaltion of heat shock protein $27 . J$. Biol. Chem. 268: 24210-24214.

Lee, J.C., J.T. Laydon, P.C. McDonnell, T.F. Gallagher, S. Kumar, D. Green, D. McNulty, M.J. Blumenthal., J.R. Heys, S.W. Landvatter, J.E. Strickler, M.M. McLaughlin, I.V. Siemens, S.M. Fisher, G.P. Livi, J.R. White, J.L. Adams, and P.R. Young. 1994. A protein kinase involved in the regulation of inflammatory cytokine biosynthesis. Nature 372: 739-746.

Lundgren, K., R.M. Walworth, M. Booher, M. Demski, M. Kirschner, and D. Beach. 1991. mik1 and wee1 co-operate in the inhibitory tyrosine phosphorylation of cdc2. Cell 64: 1111-1122.

Maeda, T., S.M. Wurgler-Murphy, and H. Saito. 1994. A twocomponent system that regulates an osmosensing MAP kinase cascade in yeast. Nature 369: 242-245.

Marshall, C.J. 1994. MAP kinase kinase kinase, MAP kinase kinase, and MAP kinase. Curr. Opin. Genet. Dev. 4: 82-89.

Maundrell, K. 1993. Thiamine repressible expression vectors pREP and pRIP for fission yeast. Gene 123: 127-130.

Millar, J.B.A. and P. Russell. 1992. The cdc25 mitotic inducer: An unconventional protein phosphatase. Cell 68: 407-410.

Millar, J.B.A., C.H. McGowan, G. Lenaers, R. Jones, and P. Russell. 1991. p $80^{\text {cdc25 }}$ is the tyrosine phosphatase that dephos- phorylates $\mathrm{p} 34^{\mathrm{cdc} 2}$ at the initiation of mitosis. $E M B O J$. 10: 4301-4309.

Millar, J.B.A., G. Lenaers, and P. Russell. 1992a. Pyp3 PTPase acts as a mitotic inducer in fission yeast. EMBO J. 11: 49334941.

Millar, J.B.A., P. Russell, J.E. Dixon, and K.-L. Guan. 1992b. Negative regulation of mitosis by two functionally overlapping PTPases in fission yeast. EMBO J. 11: 4943-4952.

Molz, L., R. Booher, P. Young, and D. Beach. 1989. cdc2 and the regulation of mitosis: six interacting mcs genes. Genetics 122: $773-782$

Moreno, S., A. Klar, and P. Nurse. 1991. Molecular genetic analysis of fission yeast Schisosaccharomyces pombe. Methods Enzymol. 194: 795-823.

Nasmyth, K. and P. Nurse. 1981. Cell division cycle mutants altered in DNA replication and mitosis in the fission yeast Schizosaccharomyces pombe. Mol. \& Gen. Genet. 182: 119124.

Nurse, P. 1975. Genetic control of cell size at cell division. Nature 256: 547-551.

. 1990. Universal control of M phase Nature 344: 503 508.

Nurse, P., P. Thuriaux, and K. Nasymth. 1976. Genetic control of the cell division cycle in the fission yeast Schizosaccharomyces pombe. Mol. \& Gen. Genet. 146: 167-178.

Ogden, J.E. and P. Fantes. 1986. Isolation of a novel type of mutation in the mitotic control of Schizosaccharomyces pombe whose phenotypic expression is dependent on the genetic background and nutritional environment. Curr. Genet. 10: 509-514.

Ottilie, S., J. Chernoff, G. Hannig, C.S. Hoffman, and R.L. Erikson. 1991. A fission yeast encoding a protein with features of protein tyrosine phosphatases. Proc. Natl. Acad. Sci. 88: $3455-3459$.

Ottilie, S., J. Chernoff, G. Hannig, C.S. Hoffman, and R.L. Erikson. 1992. The fission yeast genes $p y p 1^{+}$and $p y p 2^{+}$encode protein tyrosine phosphatases that negatively regulate mitosis. Mol. Cell. Biol. 2: 5571-5580.

Parker, L.L., S.A. Walter, P.G. Young, and H. Piwnica-Worms, 1993. Phosphorylation and inactivation of the mitotic inhibitor Wee1 by the Nim1/Cdr1 kinase. Nature 363: 736-738.

Prentice, H.L. 1991. High efficiency transformation of Schizosaccharomyces pombe by electroporation. Nucleic Acids Res. 20: 621.

Rouse, J., P. Cohen, S. Trigon, M. Morange, A. Alonso-Llamazares, D. Zamanillo, T. Hunt, and A. Nebreda. 1994. A novel kinase cascade triggered by stress and heat shock that stimulates MAPKAP kinase-2 and phosphorylation of the small heat shock proteins. Cell 78: 1027-1037.

Russell, P. and P. Nurse. 1986. $c d c 25^{+}$functions as an inducer of mitotic control in fission yeast. Cell 49: 559-567.

- 1987a. Negative regulation of mitosis by wee $1^{+}$, a gene encoding a protein kinase homolog. Cell 49: 559-567.

. 1987b. The mitotic inducer nim $1^{+}$functions in a regulatory network of protein kinase homologs controlling the initiation of mitosis. Cell 49: 569-576.

Sambrook, J., E.F. Fritsch, and T. Maniatis. 1989. Molecular cloning: A laboratory manual. Cold Spring Harbor Laboratory Press, Cold Spring Harbor, New York.

Sedgewick, S.G. and B.A. Morgan. 1994. Locating, DNA sequencing, and disrupting yeast genes using tagged Tn1000. Methods Mol. Genet. 3: 131-140.

Shiozaki, K. and P. Russell. 1995. Counteractive roles of protein phosphatases 2C (PP2C) and a MAP kinase kinase homolog in the osmoregulation of fission yeast. $E M B O J .14: 492-502$.

Sun, H., C.H. Charles, L.F. Lau, and N. Tonks. 1993. MKP-1 
Millar et al.

(3CH134), an immediate early gene product, is a dual specificity phosphatase that dephosphorylates MAP kinase in vivo. Cell 75: 487-493.

Thuriaux, P., P. Nurse, and B. Carter. 1978. Mutants altered in the control co-ordinating cell division with cell growth in the fission yeast Schizosaccharomyces pombe. Mol. \& Gen. Genet. 161: 215-220.

Warbrick, E. and P. Fantes. 1991. The Wisl protein kinase is a dose-dependent regulator of mitosis in Schizosaccharomyces pombe. EMBO I. 10: 4291-4299.

1992. Five novel elements involved in the regulation of mitosis in fission yeast. Mol. \& Gen. Genet. 232: 440-446.

Ward, Y., S. Gupta, P. Jensen, M. Wortmann, R.J. Davis, and K. Kelly. 1994. Control of MAP kinase activation by the mitogen-induced threonine/tyrosine phophatase PACl. Nature 367: 651-654.

Wu, L. and P. Russell. 1993. Niml kinase promotes mitosis by inactivating Weel tyrosine kinase. Nature 363: 738-741.

Young, P.G. and P. Fantes. 1987. Schizosaccharomyces pombe mutants affected in their division response to starvation. I. Cell Sci. 88: 295-304. 


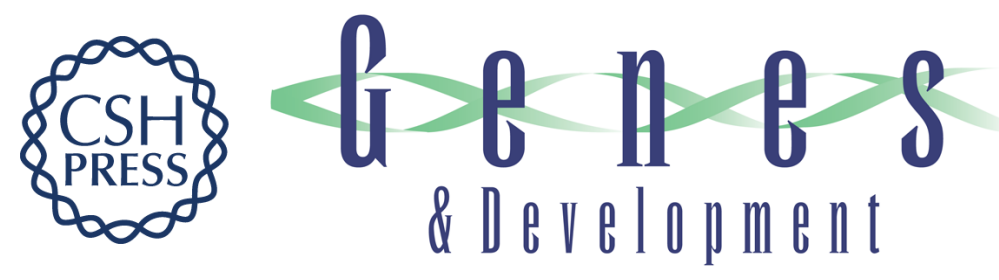

\section{Pyp1 and Pyp2 PTPases dephosphorylate an osmosensing MAP kinase controlling cell size at division in fission yeast.}

J B Millar, V Buck and M G Wilkinson

Genes Dev. 1995, 9:

Access the most recent version at doi:10.1101/gad.9.17.2117

References This article cites 56 articles, 9 of which can be accessed free at:

http://genesdev.cshlp.org/content/9/17/2117.full.html\#ref-list-1

License

Email Alerting

Service

Receive free email alerts when new articles cite this article - sign up in the box at the top right corner of the article or click here.

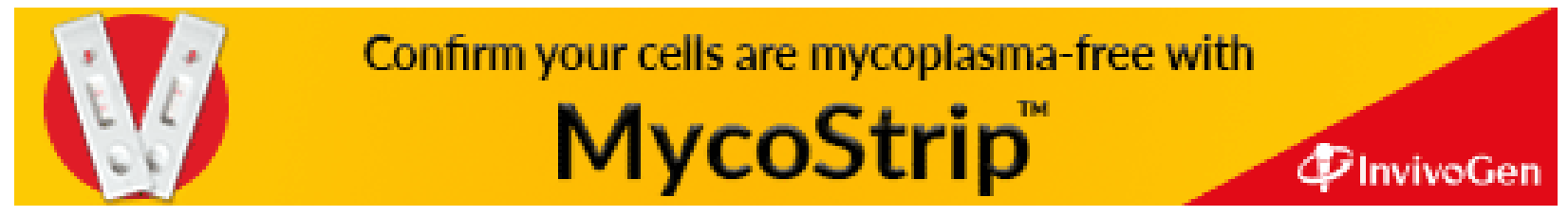

